\section{Sensation-seeking, life events and depression}

\author{
The Cardiff Depression Study
}

ANNE FARMER, KATE REDMAN, TANYA HARRIS, ARSHAD MAHMOOD, STEPHANIE SADLER and PETER MCGUFFIN
Adverse events are associated with the onset of depressive episodes (Brown \& Harris, 1978; Paykel, 1978) and there is evidence that both depression and adversity are familial and genetically influenced (Plomin \& Bergman, 1991; Thapar \& McGuffin, 1996). This familial relationship could be mediated by aspects of personality that also run in families. For example, certain personality characteristics could lead to risk-taking behaviour, which could generate an excess of adverse life events. This has been described as 'hazard proneness' (McGuffin et al, 1988), and the Sensation-Seeking Questionnaire (SSQ; Zuckerman et al, 1978) provides one method for measuring such risk-taking personality traits. In this study, we have used a sib-pair design to examine whether those who have high scores on the SSQ have more adverse events and therefore are more likely to become depressed.

\section{METHOD}

correlated negatively with depression

were familial and were correlated

positively with less severe events, but not the severe events typically associated with depressive onsets.

\section{Conclusions The SSQ measures a}

familial personality trait and depression is associated with lower scores. Although

high sensation-seeking is associated with a higher rate of life events, these carry little threat.

\section{Declaration of interest Study} funded by the WellcomeTrust.

\section{Proband and sibling recruitment}

One hundred and five probands with depression (D-probands) aged 18-65 years who fulfilled the research criteria of the International Classification of Diseases, 10th edition (ICD-10; World Health Organization, 1992) (F32 and F33) and who had a sibling (D-sib) who was willing to be studied were recruited via the psychiatric services and general practitioner lists based in Cardiff and South Gwent, Wales. Subjects with a current or prior history of psychotic or bipolar symptoms were excluded.

Age- and gender-matched control subjects (C-probands) were drawn from patients attending dental and orthopaedic out-patient clinics and from among the employees of the University Hospital of Wales National Health Service (NHS) Trust. The latter were invited to participate via a request in their wage or salary slips. The C-probands were included if they had no current or past history of depression and had a sibling (C-sib) who was willing to participate in the study. Wherever possible, the sibling nearest in age to the D-proband or the C-proband was studied. However, if this sibling was unavailable or unwilling, the sibling next in age was asked to participate. Most interviews were conducted face to face but for $18.5 \%$ of the D-sibs and $33.3 \%$ of the C-sibs telephone interviews were undertaken.

\section{Interviews and self-rating questionnaires}

All subjects were interviewed using the Schedules for Clinical Assessment in Neuropsychiatry (SCAN; Wing et al, 1990) and the Life Events and Difficulties Schedule (LEDS; Brown \& Harris, 1978). The severity and threat of events scored on the LEDS were rated contextually by an expert panel (Brown \& Harris, 1978; Farmer $e t$ al, 2000). For subjects who were depressed at the time of interview, the date of onset of the current episode was determined and life events were recorded for the 12 months prior to that date. For all non-depressed subjects, events and difficulties were recorded for the 12 months prior to interview.

All subjects also completed a number of self-report questionnaires, including the SSQ (Zuckerman et al, 1978) and the Beck Depression Inventory (BDI; Beck et al, 1961).

Information obtained at the SCAN interview was entered into the CATEGO 5 scoring program to obtain ICD-10 diagnoses and an eight-point psychopathology severity rating, the index of definition (ID) for each subject.

The Statistical Package for the Social Sciences (SPSS, version 8, for Windows) was used to create a database and to undertake the statistical analyses.

\section{RESULTS}

\section{Age and gender and sensation- seeking scores}

Age was significantly negatively correlated with SSQ scores (Pearson correlation coefficient $r=-0.49, P<0.001$ ).

The mean SSQ score for 140 male subjects was 17.79 (95\% CI $16.52-19.06)$ and for 286 female subjects it was 13.33 (95\% CI 12.54-14.13) $(t=6.09$, d.f. $=424$, $P<0.001$ ). 
The mean sensation scores for male and female subjects by each subject group are shown in Table 1. For D-probands there were no significant differences for SSQ scores by gender $(t=1.39, \quad$ d.f. $=106$, $P=\mathrm{NS})$. For the other three groups the male subjects had significantly higher SSQ scores than female subjects (D-sibs: $t=4.02$, d.f. $=106, P<0.001$; C-probands: $t=2.91$, d.f. $=103, \quad P=0.004 ; \quad$ C-sibs: $\quad t=4.03$, d.f. $=103, P<0.001$ ).

\section{Sensation-seeking and depression measures}

The SSQ scores were significantly negatively correlated with scores on the BDI $(r=-0.22, \quad P<0.001)$ and significantly negatively correlated with the CATEGO5 -derived ID $(r=-0.21, P<0.001)$.
Table 1 shows that mean SSQ scores are significantly lower for both male and female D-probands compared with the other three groups (male subjects: analysis of variance (ANOVA), $F=8.61$, d.f. $=3$ and 136, $P<0.001$; female subjects: ANOVA, $F=3.99$, d.f. $=3$ and 281, $P=0.008$ ). The ANOVAs also showed significant effects for gender and depressive status independently, but no significant interactional effects between these variables (gender: $\quad F=11.47, \quad$ d.f. $=1, \quad P=0.001$; depressive status: $F=16.42$, d.f. $=2, P<$ 0.001; gender by depressive status: $F=2.54$, d.f. $=2, P=0.08$ ).

Eight of the D-sibs were depressed at the time of interview and a further $22 \mathrm{D}$-sibs plus two of the C-sibs had experienced an episode of depression in the past but were not currently depressed. An ANOVA to examine the relationship between SSQ scores for current and past history of

Table I Mean Sensation-Seeking Questionnaire (SSQ) score and $95 \% \mathrm{Cl}$ for males and females by each subject group

\begin{tabular}{lccc}
\hline Subject group & No. of subjects & SSQ score & $95 \% \mathrm{Cl}$ \\
\hline $\begin{array}{l}\text { D-probands } \\
\text { Male }\end{array}$ & 38 & 13.18 & $10.96-15.41$ \\
Female & 70 & 11.47 & $10.11-12.83$ \\
D-sibs & 33 & & $15.53-20.35$ \\
Male & 75 & 17.94 & $11.10-13.99$ \\
Female & & 12.54 & $16.80-21.50$ \\
C-probands & 27 & & $13.08-16.30$ \\
Male & 78 & 19.15 & $18.46-23.49$ \\
Female & & 14.69 & $12.70-16.60$ \\
C-sibs & 42 & & 14.65 \\
Male & 63 & 20.98 & \\
Female & 32 & 15 & \\
\hline
\end{tabular}

D-probands, probands with depression; D-sibs, siblings of probands with depression; C-probands, control probands; C-sibs, siblings of control probands.

Table 2 Mean number of severe threatening events and less severe events over 12 months' for each subject group (with $95 \% \mathrm{Cl}$ )

\begin{tabular}{lcccc}
\hline Subject group & $\begin{array}{c}\text { Mean no. of } \\
\text { severe events }\end{array}$ & $95 \% \mathrm{Cl}$ & $\begin{array}{c}\text { Mean no. of less } \\
\text { severe events }\end{array}$ & $95 \% \mathrm{Cl}$ \\
\hline D-probands & $1.04^{2}$ & $0.76-1.31$ & 1.95 & $1.59-2.31$ \\
D-sibs & 0.52 & $0.34-0.69$ & 2.20 & $1.88-2.53$ \\
C-probands & 0.36 & $0.24-0.48$ & 2.46 & $2.08-2.83$ \\
C-sibs & 0.41 & $0.26-0.56$ & 2.26 & $1.86-2.66$ \\
\hline
\end{tabular}

I. Life events recorded for 12 months prior to illness onset for current depressed subjects and for 12 months prior to interview for non-depressed subjects.

2. D-probands have significantly more of the severe threatening events compared with the other three groups. Analysis of variance (ANOVA): $F=10.52$, d.f. $=3$ and $422, P<0.001$ ).

$D$-probands, probands with depression; $D$-sibs, siblings of probands with depression; C-probands, control probands; C-sibs, siblings of control probands. depression was therefore undertaken, dividing the subjects into 116 who were depressed at the time of interview (mean SSQ score $=11.93$, 95\% CI 10.83-13.03), 24 who reported any previous episode of depression (mean SSQ score $=14.50,95 \%$ CI 11.64-17.36) and 286 who had never been depressed (mean SSQ score $=16.00$, 95\% CI 15.10-16.89). The results showed that those who were currently depressed had significantly lower SSQ scores than the other two groups ( $F$ ratio=13.19, d.f. $=3$ and $422, P<0.001)$. However, there was no significant difference in scores between those with a past history of depression compared with those who had never been depressed ( $t=1.03$, d.f. $=28.21$, $P=$ NS).

\section{Familial patterns and SSQ scores}

The SSQ scores for D-probands and Cprobands were correlated significantly with those of their siblings $(r=0.28, P<0.001)$.

When the D-sibs were compared with the C-sibs (omitting any sibling with a current or past history of depression), the C-sibs had significantly higher mean SSQ scores (mean SSQ score for 103 Csibs $=17.31$, 95\% CI 15.66-18.96; mean SSQ score for $87 \mathrm{D}$-sibs $=14.20,95 \% \mathrm{CI}$ 12.69-15.70, $t=2.72$, d.f. $=188, P=0.007$ ).

\section{Relationship between life event measures, depression and SSQ scores}

The mean number of independent, and possibly independent, severe threatening (LEDS rated 1+2) and less severe (LEDS rated $3+4$ ) life events contextually rated, with $95 \%$ CIs for each subject group over a 12-month time frame (for currently depressed subjects this was the 12 months prior to illness onset and for non-depressed subjects it was the 12 months prior to interview), are shown in Table 2. Although Dprobands had significantly more severe events over 12 months $(F=10.52$, d.f. $=3$ and 422, $P<0.001$ ), Table 2 also shows that they had fewer less severe events compared with the other groups (although this is not statistically significant).

The SSQ scores were not correlated with the number of independent, and possibly independent, severe threatening life events reported or contextually rated over a 12-month time frame (number of severe threatening life events reported: $r=-0.06, \quad P=\mathrm{NS}$; number of severe threatening life events contextually rated: 
$r=-0.01, P=\mathrm{NS})$. This was also the case when the correlations were calculated only for the 286 subjects who had never been depressed $(r=0.01, P=\mathrm{NS})$. However, for all four groups combined the SSQ scores were correlated significantly with the number of less severe events both reported $(r=0.22, P<0.001)$ and contextually rated $(r=0.20, P<0.001)$.

\section{DISCUSSION}

\section{Age, gender and SSQ scores}

The results show that higher scores on the SSQ are associated significantly with being young and male. This is a consistent finding in the literature (Zuckerman \& Neeb, 1979; Ball et al, 1984; Zuckerman, 1994). Zuckerman (1994) noted that "sensation seeking rises between the ages of 9 and 14, peaks in late adolescence or early twenties then declines steadily with age thereafter". It has been suggested that these age and gender differences in SSQ scores could be due to either cultural differences (Zuckerman \& Neeb, 1980) or the psychometric limitations of the questionnaire (Zuckerman, 1994).

\section{SSQ scores and depression ratings}

The SSQ scores were significantly negatively associated with the BDI score (a self-report continuous measure of current depressed mood) as well as with the F32 and F33 ICD-10 operational definitions of depression and the ID derived from the SCAN interview. Thus, low mood is associated with lower SSQ scores. This is not in keeping with our hypothesis that high levels of sensation-seeking might be a common familial factor underlying predisposition to depression and life events, but it agrees with the findings of Carton $e t$ al (1992), who showed a significant negative association between SSQ score and low mood. However, the SSQ scores of the 24 subjects who had a past history of depression but who were well at interview did not differ from those of individuals who had never been depressed. This suggests that sensation-seeking returns to premorbid levels following recovery from depression.

It is possible that in those who were currently depressed there had been an association between high SSQ scores and severe threatening events before the depression, but because of their depression (and its effect in reducing the SSQ score)

\section{CLINICAL IMPLICATIONS}

- Sensation-seeking is associated with high rates of life events carrying low threat.

- Sensation-seeking is not associated with a 'hazard prone' lifestyle and does not provide an explanation for the familial clustering of both depression and life events.

- Sensation-seeking is a familial trait.

\section{LIMITATIONS}

- Sib-pair design did not allow for a strictly systematic ascertainment of depression and control probands.

- Controls selected for mental health may have magnified differences (including scores on the SSQ) between groups.

- SSQ may not be sensitive enough to measure the more subtle ways in which individuals may create 'hazardous' environments for themselves.

ANNE FARMER, FRCPsych, MRC Social, Genetic and Developmental Psychiatry Research Centre, Institute of Psychiatry, London; KATE REDMAN, PhD, TANYA HARRIS, PhD, ARSHAD MAHMOOD, MRCPsych,

STEPHANIE SADLER, MRCPsych, Department of Psychological Medicine, University of Wales College of Medicine, Cardiff; PETER McGUFFIN, FRCPsych, MRC Social, Genetic and Developmental Psychiatry Research Centre, Institute of Psychiatry, London

Correspondence: Professor Anne Farmer, MRC Social, Genetic and Developmental Psychiatry Research Centre, Institute of Psychiatry, De Crespigny Park, Denmark Hill, London SE5 8AF, UK

(First received 31 August 2000, final revision 20 December 2000, accepted 22 December 2000)

this correlation was suppressed. However, the failure to find a significant correlation between SSQ scores and severe events in the 286 subjects who had never been depressed fails to support this hypothesis.

Our study has shown also that the gender difference in SSQ scores failed to reach statistical significance in the $\mathrm{D}$ probands, which suggests that depression in male subjects may have a greater impact on the suppression of SSQ scores than in female subjects. To examine this further, an ANOVA was carried out that factored according to gender and depressed status (defined as whether the individual was currently depressed, had a past history of depression or had never been depressed). This showed independent effects for both gender and depressed status but failed to demonstrate a significant gender by status interaction. Consequently, we have not confirmed any differential effect on the lowering of SSQ scores in male subjects with depression compared with female subjects with depression.

\section{Familiality of SSQ scores}

The SSQ scores were familial, as indicated by a moderately high sib-pair correlation. When the never-depressed D-sibs and C-sibs were compared (i.e. when those siblings with a current or past history of depression were omitted from the analysis), the D-sibs had significantly lower scores compared with the $\mathrm{C}$-sibs. These findings are supportive of the view that SSQ scores represent a somewhat stable and familial personality trait. However, the reduction in the scores of those who were currently depressed indicates that the measure may be partly mood-state dependent.

\section{SSQ scores and life event measures}

The SSQ scores were not associated significantly with the type of severe threatening life events that are usually recognised as being associated with depressive onsets (Brown \& Harris, 1978; Paykel, 1978). However, SSQ scores were correlated significantly with the number of less severe events 
(those rated 3 and 4 on the LEDS scheme). Thus, as predicted, high sensation-seeking is modestly associated with being more 'event prone' but not with being 'hazard prone', if we define hazards as highly threatening events of the type commonly associated with depressive onsets.

Contrary to our original hypothesis, sensation-seeking was not found to be associated with a 'hazard prone' lifestyle and hence did not offer an explanation for the connection between familial clustering of life events and familial aggregation of depression. Indeed, depression was associated with low sensation-seeking. Although this may be partly a consequence of mood state, where currently depressed individuals tend to avoid risk-taking behaviour, we have evidence that sensationseeking has the characteristics of a familial trait: the SSQ scores were substantially correlated within our sib-pairs as a whole; and scores were significantly lower in the never-depressed D-sibs compared with Csibs. This suggests that sensation-seeking is a trait that is negatively associated with familial susceptibility to depression and, conversely, that high sensation-seeking therefore may be an indicator of resilience.
Higher SSQ scores were associated with higher rates of life events, but these were of the lower threat variety rather than the major hazards usually associated with depressive onsets. This went against our 'hazard prone' hypothesis as the mediating factor between adversity and familial depression, and instead suggests that although sensation-seeking is indeed associated with an eventful life the happenings that occur tend to be benign.

\section{REFERENCES}

Ball, I. L., Farnill, D. \& Wangeman, J. (1984) Sex and age differences in sensation seeking. Some national comparisons. British Journal of Psychology, 75, 257-265.

Beck, A. T., Ward, C. H., Mendelson, M., et al (1961) An inventory for measuring depression (BDI). Archives of General Psychiatry, 4, 56I-57I.

Brown, G.W. \& Harris, T. O. (1978) Social Origins of Depression. A Study of Psychiatric Disorder in Women (5th edn). London: Routledge.

Carton, S., Jouvent, R., Bungener, C., et al (1992) Sensation-seeking and depressive mood. Personality and Individual Differences, 13, 843-849.

Farmer, A., Harris, T., Redman, K., et al (2000)

Cardiff Depression Study. A sib-pair study of life events and familiality in major depression. British Journal of Psychiatry, 176, 150-155.
McGuffin, P., Katz, R. \& Bebbington, P. (1988) The Camberwell Collaborative Depression Study. III. Depression and adversity in the relatives of depressed probands. British Journal of Psychiatry, 152, 775-582.

Paykel, E. S. (1978) Contributions of life-events to causation of psychiatric illness. Psychological Medicine, 8 245-253.

Plomin, R. \& Bergman, C. S. (199I) The nature of nurture: genetic influences on 'environmental' measures. Behaviour and Brain Sciences, 14, 373-427.

Thapar, A. \& McGuffin, P. (1996) Genetic influences on life-events in childhood. Psychological Medicine, $\mathbf{2 6}$, 813-820.

Wing, J. K., Babor, T., Brugha, T., et al (1990) SCAN: Schedules for Clinical Assessment in Neuropsychiatry. Archives of General Psychiatry, 47, 589-593.

World Health Organization (1992) Tenth Revision of the International Classification of Diseases and Related Health Problems (ICD-I0). Geneva: WHO.

Zuckerman, M. (1994) Behavioural Expressions and Biosocial Bases of Sensation-Seeking. Cambridge: Cambridge University Press.

\& Neeb, M. (1979) Sensation-seeking and psychopathology. Psychiatry Research, I, 255-264.

_ \& _ (1980) Demographic influences in sensationseeking and expressions of sensation-seeking in religion, smoking and driving habits. Personality and Individual Differences, I, 197-206.

_, Eysenck, S. \& Eysenck, H. J. (1978) Sensationseeking in England and America: Cross cultural, age and sex comparisons. Journal of Consulting and Clinical Psychology, 46, 139-149. 